column locates the ordinary events of history (beginning of the English Civil War) or 'non-scientific' aspects of their story (publication of Freud's Jokes and Their Relation to the Unconscious, introduction of Oreo cookies by the National Biscuit Company). Their timespan is shorter than Asimov's: they also end in 1988 but don't begin until $2,400,000 \mathrm{BC}$. The spare, atomistic approach to separate bits of information makes the book impossible simply to read. But a series of nine overviews (for example "Science after World War II") and more than 100 short essays provide some social and intellectual context for entries such as "A. Meissner invents a radio transmitter with vacuum tubes" (1913), "Permanent press clothing is introduced" (1964) or "Ernst Chladni invents the euphonium, a musical instrument in the tuba family" (1789).

The assiduous reader of Asimov would not have picked up any of these latter facts. For Asimov, the key dates for the radio are 1895 (radio antennae), 1901 (Marconi's sending of radio signals from England to Newfoundland), 1904 (J.A. Fleming's rectifier), 1906 (R.A. Fessenden's work on amplitude modulation), 1916 (E.H. Armstrong's superheterodyne receiver), 1939 (Armstrong's perfection of frequency modulation), 1948 (transistors) and 1954 (improvements in the transistor). For Hellemans and Bunch, there are at least 21 key moments, in addition to Meissner's work. For them, the radio antenna did not properly appear until 1905, Armstrong's superheterodyne receiver came in 1918 and Armstrong perfected frequency modulation radio in 1933. These authors agree with Asimov on the other dates, they also add a number of other moments in the history of radio.

Discrepancies also emerge in crosschecking through a year rather than a subject. Take 1922, for instance. Asimov writes of Leonard Woolley's excavation of Ur (dated to 1918 in Hellemans and Bunch, where his name is spelled Wooley); Howard Carter's discovery of Tutankhamen's tomb (confirmed by $\mathrm{H}$ and B); Herbert Evans's work on what became known as vitamin $\mathrm{E}$ (confirmed by $\mathrm{H}$ and $\mathrm{B}$, although with the addition of K. J. Scott); Evans's research on growth hormone (not mentioned at all in $\mathrm{H}$ and $\mathrm{B})$; Alexander Fleming's isolation of lysozyme (dated to 1921 in $\mathrm{H}$ and B); Oparin's work on the origin of life (under 1936 in H and B); experiments of J. Erlanger and H.S. Glasser on nerve conduction (recorded by $\mathrm{H}$ and B under 1944, when the Nobel prize was awarded); and A.A. Friedmann's work on the expanding Universe (confirmed by $\mathrm{H}$ and $\mathrm{B}$ ).

Who would want to be an anniversarial scientist when there is so much uncertainty about the facts of history, to say nothing of their interpretation? Not I, which is why I have steadfastly refused to adjudicate between Asimov and Hellemans and Bunch. It would, after all, simply be my reference books against theirs, and since they have declined to reveal theirs, it would be an unequal contest. I have reason to believe, however, that Leonard Woolley spelled his name thus.

W. F. Bynum is at the Wellcome Institute for the History of Medicine, 183 Euston Road, London NW1 2BP, UK.

\section{Of thoughts past}

\section{Graham Ritchie}

Ancient Britons and the Antiquarian Imagination: Ideas from the Renaissance to the Regency. By Stuart Piggott. Thames \& Hudson: 1989. Pp. 175. £14.95, \$19.95.

As excavation techniques extend the range of what can be recovered, and theoretical considerations crowd into university curricula, archaeology increasingly turns to science. How important it is, therefore, that in the history of ideas about early British antiquity we should be aware of the attitudes of early scholars and have an appreciation of the framework within which their thinking took place. Stuart Piggott's perceptive exploration of antiquarian ideas draws together many their own views of the world. It is a measure of Piggott's success that within this rigorous approach the reader is so pleasurably taken on a voyage of exploration through the worlds of the computation of Biblical chronologies, ancient giants and what happened after the Flood.

The Indians and Eskimos - even a Brazilian king - who were transported from the New World to be paraded before the European public in the course of the sixteenth century had a considerable effect on antiquarian approaches and on the way in which early Britons were depicted. It is startling to realize that at least a thousand Red Indians were brought back to Europe by early voyagers and that Frobisher brought Eskimos back from his expeditions to South Baffin Island in 1576-77. Early antiquaries drew comparisons between aspects of American Indian and Eskimo characteristics and those of the ancient Britons. Ethnographical illustration had a great deal of influence on the way that early man was depicted, and Piggott has assembled an unusual series of illustrations of Eskimos, Britons and, most enchanting, Picts and other North British tribesmen.

The fieldwork and recording of monuments by John Aubrey and Edward Lhuyd are set within the context of the day. Our current understanding of monuments such as Stonehenge, Avebury and the Rollright Stones begins with observations made three centuries ago. Thus William Stukeley is seen on the one hand "as a field

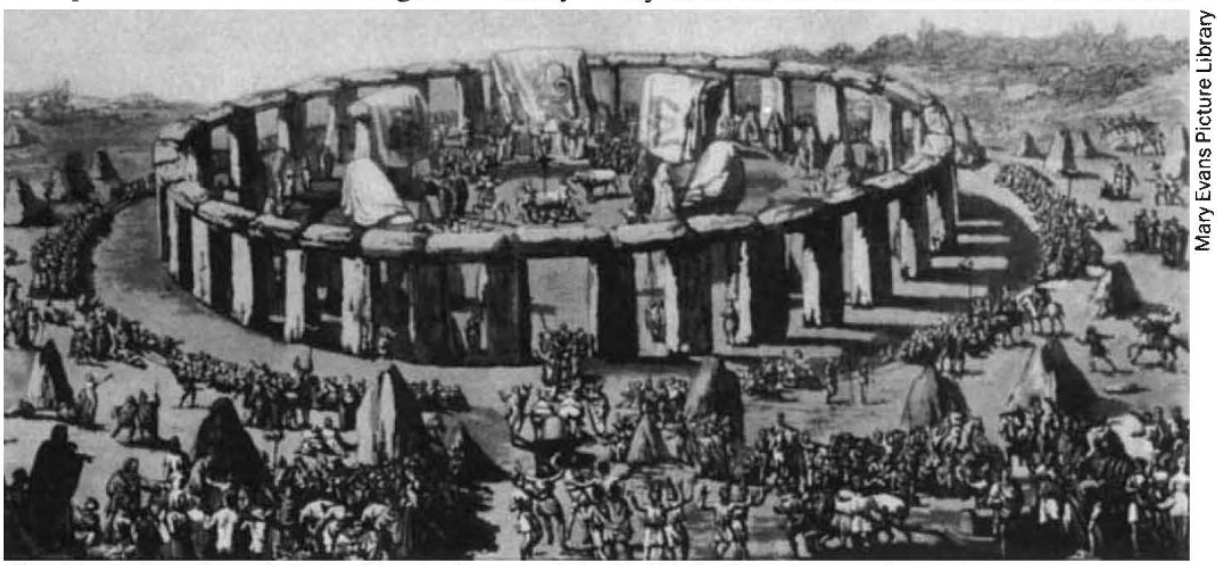

Hard facts? - Stonehenge, like Avebury and the Rollright Stones, inspired a "fantastic past for ancient Britain, dominated by fictitious Druids".

strands of research to create a fascinating picture of the intellectual worlds of wellknown figures such as Aubrey and Stukeley, and at the same time introduces many lesser known writers from the late sixteenth to the early nineteenth centuries.

The past must be understood within the intellectual constructs of the time, and thus we are not introduced to approaches to prehistory - for the term prehistoric was first used by Daniel Wilson in 1851 but to a world for which the chronology of early times was outlined in the Old Testament. The early antiquaries are to be seen as individuals undertaking research within

archaeologist of great distinction" and on the other as the man who misled generations "as the inventor and propagator of a fantastic past for ancient Britain, dominated by fictitious Druids" (p. 122). Stukeley's fieldwork at Avebury and Stonehenge is the earliest detailed recording of field monuments; between 1719 and 1724 he spent up to two months at a time surveying them using a theodolite, and making notes and drawings. In a way that we think of as 'modern', Stukeley's concern was to put on record monuments at risk from agricultural and building developments. 
Piggott sets in context the decline in scientific endeavour in the decades following 1700 , and leads us through to the campaigns of barrow-digging in Wiltshire a century later. Some archaeologists today belong to the traditions formulated at that time, and I can feel much sympathy for the "young antiquary, who, from practice, can open a barrow as nicely as you could cut up an apple pye; and from his description, it is done much after the same manner" (p. 156). Archaeologists need to understand how our attitudes to the past have been moulded.

In this volume Stuart Piggott draws together themes that he has discussed in his studies of the Druids, in his collected essays on antiquarianism, Ruins in a Landscape, and in his biography of William Stukeley. Here they are put within an historical and cultural setting that is both accessible and authoritative.

Graham Ritchie is at the Royal Commission on the Ancient and Historical Monuments of Scotland, 54 Melville Street, Edinburgh EH3 7HF, UK.

\section{Complex stability}

\section{Paul Colinvaux}

Thinking Green: An Anthology of Essential Ecological Writing. Edited by Michae Allaby. Barrie \& Jenkins, London: 1989. Pp.260.£14.95.

IN its issue of 23 September 1989, The Economist carried a review of the economies of Third World countries. The conclusion was that whether these economies caused disastrous poverty, or wealth like the dragons of Asia, depended only on whether the governments are good or bad, and no mention was made of possible limits to growth on a finite Earth. Writers in the environmentalist 1970s saw things differently. Their concern was for the miserable social consequences of human numbers rising beyond some critical density, or for the fouling of the human nest by industry. Both views are surely right.

But in their anxiety to tell their dreadfu truths, the 'green' writers made what Sherlock Holmes called "the capital mistake" of reasoning beyond their data. Their predictions of famines and shortages and limits and catastrophes were not warranted by what we knew. Readers of The Economist can therefore ignore them, even as green philosophies begin to mould the politics of the industrial states.

Thinking Green is a first-class anthology of extracts from the sacred texts of the greens, 45 short essays in all. Silent Spring, The Commons, Malthus, The Population Bomb and Spaceship Earth; all are here, together with their many supporters and a tiny few of their opponents. The extracts are short, mercifully so in the case of the wearisome establishment rewrites of such documents as The Brandt Report, and of Global 2000 and Blueprint for Survival. But the propagandists themselves are generally a very good read. Rachel Carson is superb, standing out even among essays that include Charles Dickens writing on 'Coketown'. This is a book around which to build a seminar for our times.

But the seminar will have to acknowledge much error on the path to truth. Green thinking is riven by longing for a superorganismic Earth that never was. Green writers declared that the complex was stable and the simple not. Almost no modern ecologist will accept this; mathematics, empirical data and the process of natural selection are all against it. Yet the mystical belief in an organic nature not to be trifled with lingers on. Global 2000 had in its opening sentence the idiot assertion that the coming world would be "less stable ecologically", and

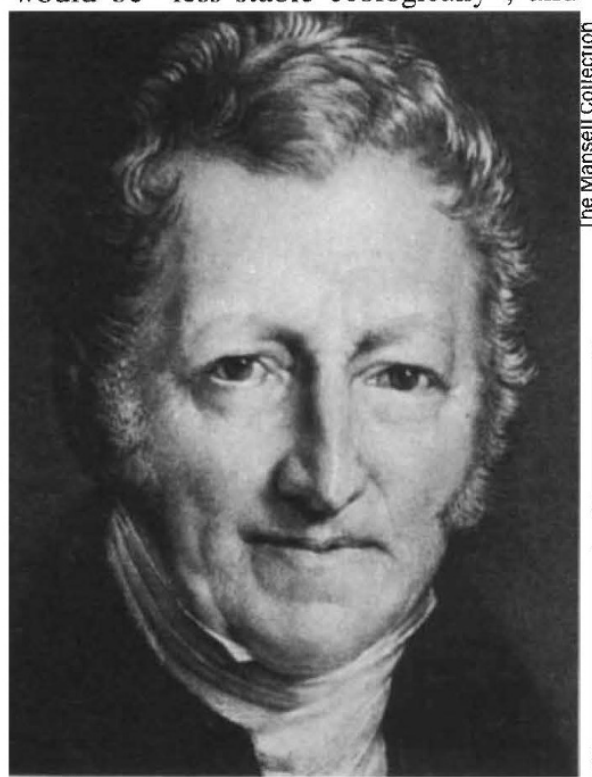

Thomas Malthus - original thinker. this was 6 years after Robert May's demonstration of the falseness of complexity-stability theory. The latest reincarnation of a superorganismic Earth is complete with a name from the myths whence it came, 'Gaia', and is allotted two extracts.

The central catch phrase of Malthus, that food supplies grow arithmetrically whereas populations grow geometrically, has proved meaningless. Food supplies have often been increased exponentially for prolonged periods. And human beings do not breed like animals, but do so under conscious parental choice subtly affected by cultural values. Malthus himself knew this, and in the extract from his Essay on Population declaims against the "viciousness" that follows times when men elect not to marry.

Mercifully, green propagandists now also realize that they were grievously misled by those who threatened us with a loss of atmosphere as the wages of pollution, so that none of the extracts in the book include ponderings about our running out of oxygen because of the poisoning of plants in the sea. The editor must have chosen his material with care.

With these essential criticisms in the open, the core of Thinking Green describes the true dilemmas of our times. The good life requires access to a diverse nature, people in tolerable densities and freedom of choice, qualities that are not so easily provided as is the 'wealth' that economists measure.

The numbers of people can be contained, if we have the patience of generations, as we must. The curse of excessive families is a cultural curse, not a biological one. We do act to regulate our reproduction, even the poorest of us when settled in stable cultures. If we think with the green writers, as I do, that the sooner we bring the numbers down the better, then there is an easy way. Liberate women completely, in culture after culture, so that female lives are fully equal in opportunity to those of men. Can anyone doubt that women so liberated would, on the average, decide to have fewer children?

Some environmental abuses are solvable by law, although neither the laws nor the methods of enforcement have yet been devised. The tragedy of the commons is being played out in the world oceans as Asian ships with 30-mile nets strip out all large living things; world law and warships could correct this, as they did for a different form of piracy long ago.

The misery of peasants in lands once parts of Spanish and British empires comes in part because productive land was taken from them to grow cash crops to support Spanish and English gentry, a way of life that is retained by their local, gentrified successors. In the English heartland of the industrial revolution, subsidized industry - posing as farming - tears down the beauty, albeit artificial, of the countryside to grow sugar beet that no one needs. And the tragedy of sugar production is but a repertory-company version of the grander tragedy being acted out in the Amazon basin.

Politics and law are the only tools that can be used to redress these assaults on decent living. So the greens turn political. Alas they also turn socialist, despite the warnings from the Soviet Union and military dictatorships alike that state control does not lead to the preservation of land or biological diversity. But green thinking is inside politics to stay and the greens may yet be the law-givers.

Paul Colinvaux is in the Departments of Zoology and Anthropology, The Ohio State University, 1735 Neil Avenue, Columbus, Ohio 43210, USA. 